\title{
NEWS FROM THE INTERNATIONAL FEDERATION OF ROBOTICS
}

75,500 robots were installed in 1995 , according to the latest statistics issued by the International Federation of Robotics in association with the United Nations Economic Commission for Europe. IFR now estimates the world's robot population to be 650,000 units, a rise of $6 \%$ from last year's figures.

The Japan Robot Association reports that 36,563 robots were installed in Japan in 1995 and estimates that 387,290 robots were installed in that country between 1986 and 1995 inclusive. Japan therefore accounts for $59.6 \%$ of the world stock of robots and $48.4 \%$ of last year's additions.

The cost of robots is coming down. In 1991, according to IFR data, the 'average' price of a robot was US\$ 108,000 ; last year, the 'average' price was US $\$ 82,000$. Typically a robot accounts for only $30 \%$ of the cost of a 'cell' comprising a robot and ancillary equipment.

The IFR survey found that for every 10,000 people employed in the motor vehicle manufacturing industrywhich continues to remain the major user of robots worldwide-there were about 800 robots in Japan, 400 in Italy, 300 in the U.S., 250 in Sweden, 230 in Germany, and 200 in each of France and the U.K.

Welding remains the predominant robot application area. Of the 1995 installations, $73 \%$ were devoted to welding in Hungary, $52 \%$ in the U.S., $48 \%$ in Spain, $47 \%$ in Australia and $46 \%$ in the U.K.

Assembly was the largest robot application area in Singapore where it accounted for $84 \%$ of new installations, in Japan (47\%) and in Finland (26\%).

The Republic of Korea has an estimated robot population of 20,000 , of which 6,336 robots are last year's additions. Korea has now become the world's fifth largest robot user after Japan, US, Germany and Italy.

The density of robots in Singapore has increased remarkably, with a robot population now estimated be 11,790 compared with a human population of about $3,000,000$.

The IFR forecasts that the number of robots installed each year will continue to grow. It projects sales of 90,000 robots in 1996 and 143,000 in 1999.

Canada has joined the growing number of IFR member associations having a presence on the World Wide Web. At the Web address http://www.precarn.ca/ you can find the 'home page' of Precarn Associates Inc., a not-for-profit industry-led consortium that performs market-orientated collaborative research and development activities in the broad area of 'intelligent systems'. Precarn is part of the Canadian Institute for Robotics and Intelligent Systems (IRIS) network which has received considerable financial support from that country's federal and provincial governments as well as from industry.

(Submitted by Michael Kassler, Member, Executive Committee, International Federation of Robotics) 